\title{
Produção orgânica de mudas de essências florestais nativas e distribuição em comunidades rurais do semiárido paraibano
}

\author{
Natália Lara Ferreira da Silva ${ }^{1}$, Francisca Lacerda da Silva ${ }^{2}$, Alex Serafim de Lima ${ }^{3}$, Emmanuelly Calina Xavier \\ Rodrigues dos Santos ${ }^{4}$, José Paulo Costa Diniz, José Geraldo Rodrigues dos Santos *6 \\ Universidade Estadual da Paraíba, ${ }^{1}$ laranatalia75@gmail.com; ${ }^{2}$ franciscalacerdadasilva@ @otmail.com; \\ 3alexcdf14@gmail.com; ${ }^{4}$ emmanuelly.xavier@gmail.com; ${ }^{5}$ josepaulo.rc06@gmail.com; \\ 6*josegeraldo@ccha.uepb.edu.br.
}

\begin{abstract}
RESUMO: Associado à degradação ambiental, o uso irracional de essências florestais nativas com fins farmacêuticos, industriais e medicinais, através da exploração das folhas, cascas, raízes e frutos, pode levar ao desaparecimento destas espécies. No bioma Caatinga, diversas espécies já integram a lista de ameaçadas de extinção. Contudo, são necessários meios rápidos e eficazes para a reversão dos efeitos negativos causados pela ação do homem. O projeto teve como objetivo contribuir para o reflorestamento de áreas degradadas na microrregião de Catolé do Rocha/PB com a produção e distribuição de mudas de florestas nativas da Caatinga. O projeto foi executado em condições de viveiro, na Universidade Estadual da Paraíba, Catolé do Rocha-PB, e consistiu na produção de 250 mudas orgânicas de aroeira, 250 mudas de cumarú, 250 mudas de sabiá e 250 mudas de mororó. Após a produção, as mudas foram distribuídas às comunidades rurais da microrregião de Catolé do Rocha, em que foram feitas algumas apresentações a respeito da importância de preservar o bioma Caatinga e o meio ambiente em si, reintroduzindo essas essências florestais à natureza.
\end{abstract}

PALAVRAS-CHAVE: Mudas florestais; Preservação ambiental; Reflorestamento.

\section{INTRODUÇÃO}

Cobrindo originalmente uma área de $826.411 \mathrm{~km}^{2}$ aproximados, ocupando $70 \%$ da região nordeste e $10 \%$ do território nacional, a caatinga, um bioma exclusivamente brasileiro, possui rica biodiversidade e espécies exclusivas. Somente da flora, apresenta 1981 espécies vegetais registradas, sendo 318 espécies endêmicas, ou seja, que não são encontradas em nenhuma outra parte do Planeta (MARTINELLI e MORAES, 2013). A caatinga é caracterizada por plantas adaptadas a escassez de água e por uma diversidade de paisagens que mudam de forma ao longo do ano devido ao caráter sazonal das chuvas e a condição de semiaridez deste bioma, onde a maior parte das plantas perde suas folhas no período seco, tendo sua renovação logo no início das chuvas. Associado à degradação ambiental, o uso irracional de essências florestais nativas com fins farmacêuticos, industriais e medicinais, através da exploração das folhas, cascas, raízes e frutos, pode levar ao desaparecimento destas espécies (PEREIRA, 2011).

$\mathrm{Na}$ caatinga, as espécies aroeira (Myracrodruon urundeuva), braúna (Schinopsis brasiliensis), jacarandá (Jacaranda rugosa), cumarú (Amburana cearensis) e ipê amarelo (Tabebuia selachidentata) já integram a lista de espécies ameaçadas de extinção (PAES et al., 2004). Contudo, são necessários meios rápidos e eficazes para a reversão dos efeitos negativos causados pela ação do homem. Desta forma, algumas medidas que podem permitir a recuperação deste bioma, são: criação de áreas protegidas (unidades de conservação), promoção de práticas conservacionistas de manejo das florestas e do solo, ações de reestruturação do ambiente afetado, produção de mudas nativas para o reflorestamento de áreas desmatadas para a recomposição da vegetação e a reintrodução da fauna nativa (ICMBIO, 2018).

No entanto, o conhecimento sobre a produção de mudas de espécies nativas da caatinga ainda é incipiente e escasso e esse conhecimento é de fundamental importância para a recuperação de áreas degradadas no bioma. A restauração florestal tem como premissa a utilização de elevada diversidade vegetal como forma de garantir a sustentabilidade das comunidades restauradas e reduzir os custos desse tipo de trabalho (MARTINS, 2007; RODRIGUES et al., 2007). Nesse contexto, a utilização de metodologias alternativas de restauração que enfocam aspectos ecológicos que regem a sucessão ecológica e a organização das comunidades florestais tem ganhado grande destaque nos últimos anos.

A aroeira (Myracrodruon urundeuva Allemão) é uma espécie arbórea muito conhecida no Nordeste do Brasil devido às suas propriedades farmacológicas, sendo considerada uma das principais plantas medicinais da região (ALBUQUERQUE et al., 2007). O cumarú (Amburana cearenses) é uma espécie arbórea de porte médio, com grande potencial ornamental por apresentar floração vistosa e suas flores fornecem recursos fundamentais para a manutenção das populações de abelhas nativas. Além disso, o cumaru é uma espécie pioneira muito importante em reflorestamentos de áreas degradadas. (GARIGLIO et al., 2010). O sabiá (Mimosa caesalpiniifolia Benth.), pertencente à família Fabaceae, é uma espécie arbórea que ocorre naturalmente no Maranhão e na caatinga nordestina brasileira, sendo conhecida popularmente por sansão-do-campo ou sabiá. Trata-se de espécie de rápido crescimento, que pode ser cortada com apenas três anos de idade e aceita cortes subsequentes, produz madeira pesada, resistente à umidade e excelente para estacas, lenha, carvão, forquilha e esteios, além de ser empregada como cerca viva defensiva e recomendada para a recuperação de áreas degradadas (RIBASKI et al., 2003). O mororó (Bauhinia cheilantha (Bong.) Steud.) é uma espécie

Caderno Verde de Agroecologia e Desenvolvimento Sustentável (ISSN 2358-2367) v. 9, n.7, e-7040, 2019 doi: $10.18378 /$ cvads.v9i7.7040 
SILVA, N. L. F. et al. Produção orgânica de mudas de essências florestais nativas e distribuição em comunidades rurais do semiárido paraibano. In: II Congresso Paraibano de Agroecologia \& IV Exposição Tecnológica, 2019. Anais... Caderno Verde de Agroecologia e Desenvolvimento Sustentável, Pombal, v. 9, n.7, e-7040, 2019.

pertencente à família das leguminosas, muito utilizada na Caatinga como forrageira, principalmente na época da seca. Conhecida popularmente como pata-de-vaca, ganhou fama por ter em suas folhas compostos químicos como os heterosídeos e os alcalóides, que ajudam a controlar as taxas de glicose (LORENZI e MATOS, 2008).

A utilização de resíduos orgânicos de origem animal ou vegetal, tais como estercos, compostos orgânicos, húmus de minhoca e biofertilizantes, tem sido empregada com sucesso para a fertilização dos solos (MELLO e FERNANDES, 2000). O uso destes adubos naturais em frutíferas tem sido bastante estudado, Lima et al. (2018) e Silva et al. (2019) ao estudarem a produção da videira Isabel em condições semiáridas obtiveram resultados satisfatórios com o uso destes insumos orgânicos advindos de propriedades rurais. Fisicamente, os biofertilizantes contribuem para a melhoria da estrutura e aeração do solo, elevando o potencial de fertilidade, que resulta em plantas nutricionalmente mais equilibradas. O biofertilizante também é usado como adubo foliar e para aumentar a resistência da planta contra pragas e doenças, por conter na sua fórmula alguns elementos coadjuvantes do controle fitossanitário (FERNANDES et al., 2000).

Objetivou-se com o presente trabalho propagar espécies da Caatinga, para fins de reflorestamento e doação de mudas para comunidades rurais e conscientizá-los sobre a importância da reintrodução de essências florestais nas áreas degradadas da microrregião de Catolé do Rocha/PB.

\section{MATERIAL E MÉTODOS}

O projeto foi executado por estudantes de Licenciatura Plena em Ciências Agrárias no Centro de Ciências Humanas e Agrárias, da Universidade Estadual da Paraíba - UEPB, no setor de agroecologia, Campus-IV, distando 2 km da sede do município de Catolé do Rocha, que está situado na região semiárida do estado da Paraíba. A área experimental está localizada nas coordenadas de Latitude $6^{\circ} 20^{\prime} \mathrm{S}$, Longitude $34^{\circ} 44^{\prime}$ e altitude de 275 m (Mascarenhas et al., 2005). Consistiu na produção de 250 mudas orgânicas de aroeira, 250 mudas de cumarú, 250 mudas de sabiá e 250 mudas de mororó, em condições de viveiro.

O trabalho inicial consistiu no plantio das sementes de aroeira, cumaru, sabiá e mororó em sacos plásticos, com tamanho de 15 x $30 \mathrm{~cm}$, tendo uma capacidade para acumular cerca de $2 \mathrm{~kg}$ de substrato, composto de uma mistura de terra barrenta, esterco bovino peneirado e areia, em proporções iguais. As adubações foliares das mudas foram realizadas, via fertirrigação, utilizando-se um biofertilizante enriquecido, produzido a base de $70 \mathrm{~kg}$ de esterco verde de vacas em lactação, 120 litros de água, $4 \mathrm{~kg}$ de farinha de rocha MB4, $2 \mathrm{~kg}$ de cinza de madeira e $5 \mathrm{~kg}$ de folhas de leguminosas, além de $5 \mathrm{~kg}$ de açúcar ou melaço e $5 \mathrm{~kg}$ de leite para acelerar o metabolismo das bactérias. $\mathrm{O}$ biofertilizante foi aplicado, quinzenalmente, utilizando-se uma concentração de $20 \mathrm{~mL} / \mathrm{L}$ ou $2 \%$, sendo produzido, de forma anaeróbia, em recipiente plástico com tampa, com capacidade individual para 240 litros, contendo uma mangueira ligada a uma garrafa plástica com água para retirada do gás metano produzido pela fermentação do material através de microrganismos (bactérias), segundo metodologias propostas por Santos e Santos (2008).

Para a irrigação, foi utilizado um sistema localizado pressurizado, utilizando-se uma bomba Danco de 2 CV. A condução da água está feita através de canos de PVC de 2 polegadas e mangueira de $16 \mathrm{~mm}$, além de microaspersores, com vazão de $120 \mathrm{~L} \cdot \mathrm{h}^{-1}$, instalados de forma invertida em duas linhas mangueiras ao longo do viveiro. A água utilizada para as irrigações das mudas foi captada de um poço amazonas, não apresentando problemas de salinidade. A etapa final consistiu da distribuição de mudas orgânicas para 150 produtores rurais de base familiar de 20 comunidades rurais de 10 municípios da microrregião de Catolé do Rocha/PB. A escolha das comunidades obedeceu aos seguintes critérios: receptividade das famílias rurais, existência de áreas desmatadas que possam ser recuperadas com o plantio das mudas e disponibilidade de água suficiente para irrigação. O projeto teve a duração de 12 meses, sendo iniciado em outubro de 2017 e concluído em setembro de 2018.

\section{RESULTADOS E DISCUSSÃO}

Os resultados obtidos foram divulgados para produtores de base familiar das comunidades beneficiadas. Foram realizadas palestras e distribuição de boletins técnicos visando o aprimoramento dos conhecimentos sobre tecnologias para produção de mudas orgânicas de essências florestais nativas. Entendemos que a difusão de tecnologia sobre produção de mudas orgânicas de essências florestais nativas contribui para a preservação do meio ambiente, que é sinônimo de saúde e prosperidade para a população rural. Produtores rurais de base familiar de 20 comunidades rurais em 10 municípios da microrregião de Catolé do Rocha/PB (Figuras 1 e 2). 
SILVA, N. L. F. et al. Produção orgânica de mudas de essências florestais nativas e distribuição em comunidades rurais do semiárido paraibano. In: II Congresso Paraibano de Agroecologia \& IV Exposição Tecnológica, 2019. Anais... Caderno Verde de Agroecologia e Desenvolvimento Sustentável, Pombal, v. 9, n.7, e-7040, 2019.

Figuras 1 e 2 - Produção de mudas de essências florestais orgânicas no viveiro da UEPB, Catolé do Rocha/PB, 2019.

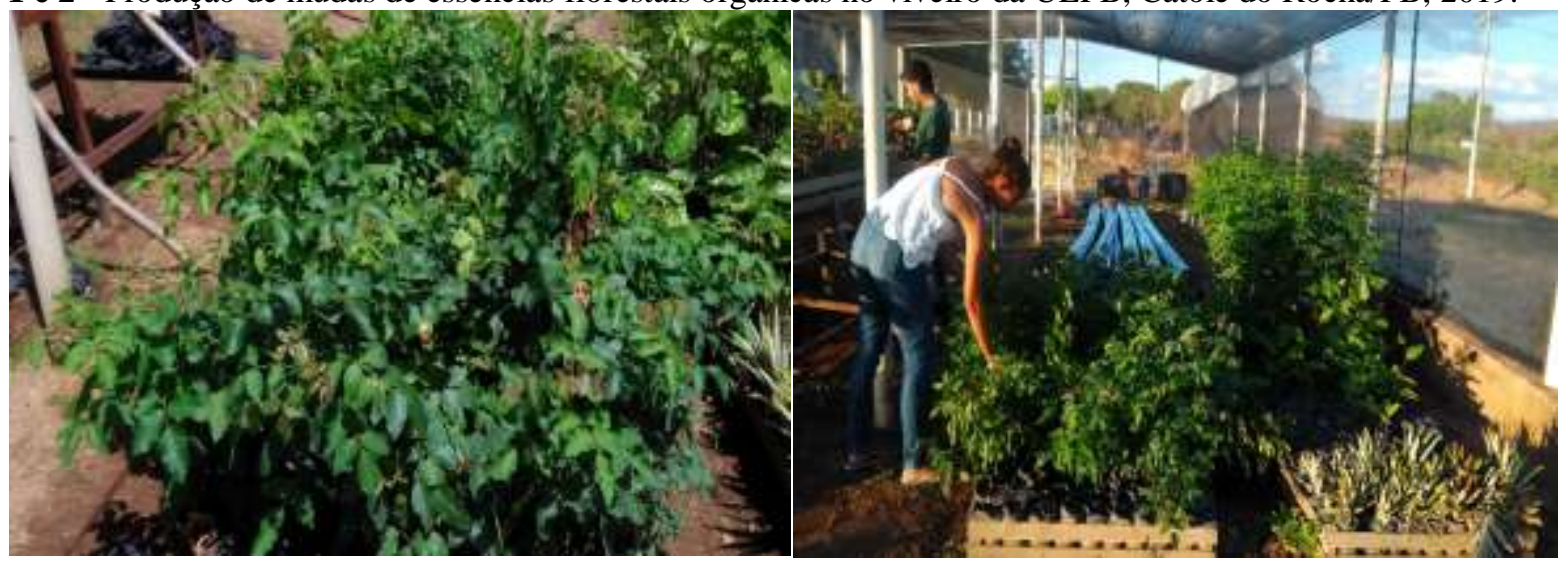

Fonte: Do próprio autor (2019).

Os eventos de extensão foram realizados, de forma contínua, à medida que as mudas eram distribuídas nas comunidades rurais, e constaram de visitas técnicas, palestras e distribuição de folderes (Figura 3). As comunidades rurais tiveram a oportunidade de compreender o bioma que os cerca, e que ficaram convictos de que por muito tempo a Caatinga foi caracterizada como um Bioma homogêneo, pouco degradado e provido de poucas espécies endêmicas, com baixa diversidade (LEAL et al., 2005). No entanto, sabe-se que a Caatinga contém uma grande biodiversidade florística, com elevado número de espécies e táxons raros e endêmicos que, atualmente, vem sofrendo modificações fitofisionômicas e estruturais originadas por processos antrópicos, principalmente, a exploração irracional das espécies madeireiras, as queimadas desordenadas, o desmatamento para exploração de lenha para carvão e a erosão dos solos que impendem o desenvolvimento das plantas no campo (SILVA, FELIZMINO e OLIVEIRA, 2015). Por isso é importante a reimplantação das essências florestais nos biomas brasileiros, sendo que o projeto discutido torna um exemplo para outras regiões brasileiras, na ênfase de preservar os recursos naturais através do uso da adubação orgânica.

Figura 3 - Distribuição de mudas orgânicas de essências florestais para comunidades rurais da microrregião de Catolé do Rocha, 2019.

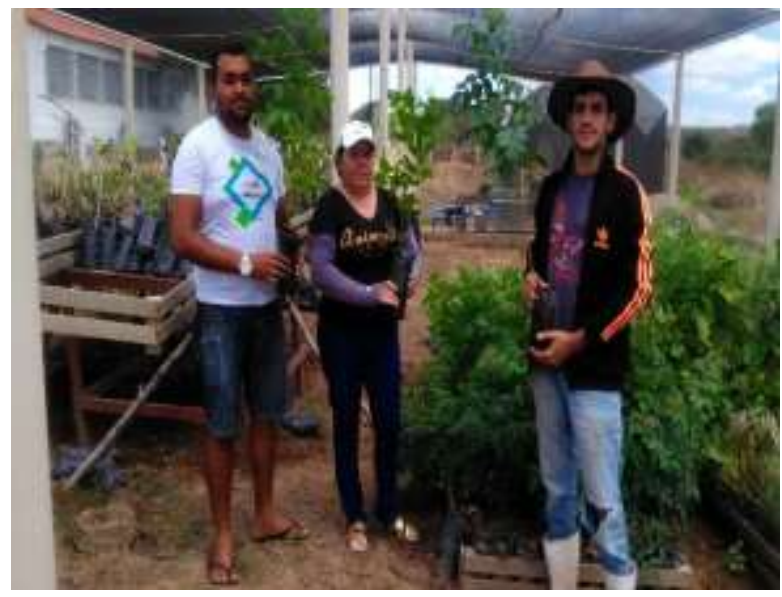

Fonte: Do próprio autor (2019).

Dentre as frutíferas nativas da Caatinga, destacam-se o umbuzeiro, cajueiro, juazeiro e trapiá, e dentre as forrageiras arbustivas e arbóreas destacam-se o juazeiro, o mororó, o jucazeiro, a catingueira, o sabiá e a catanduva que são utilizadas como o único pasto disponível para gado, na época da estiagem (Reserva da biosfera da Caatinga, 2008). Uma alternativa para evitar a destruição da Caatinga é a criação de Unidades de Conservação (UC), trata-se de uma das estratégias mais importantes para garantir a conservação da diversidade biológica de uma região (MARGULES e PRESSEY, 2000), e estes princípios de preservação foram os mais discutidos entre as comunidades rurais que tiveram como relevante este projeto na reintegração das essências florestais no semiárido paraibano.

\section{CONCLUSÕES}

A atividade contribuiu para o resgate e a valorização de conhecimentos locais úteis no plantio, manejo, conservação e uso sustentável da biodiversidade, bem como identificar, possíveis ameaças à biodiversidade e apontar estratégias de manejo para fins de conservação e uso sustentável. 
SILVA, N. L. F. et al. Produção orgânica de mudas de essências florestais nativas e distribuição em comunidades rurais do semiárido paraibano. In: II Congresso Paraibano de Agroecologia \& IV Exposição Tecnológica, 2019. Anais... Caderno Verde de Agroecologia e Desenvolvimento Sustentável, Pombal, v. 9, n.7, e-7040, 2019.

O projeto exerceu um impacto socioambiental positivo, favorecendo a população atual e as futuras gerações que viverão e desfrutarão dos benefícios de espaços mais verdes, tendo como exemplo a preservação consciente do único bioma exclusivamente brasileiro.

\section{REFERÊNCIAS}

ALBUQUerque, U. P, MEDEIROS, P. M, ALMEIDA, A. L, MONTEIRO, J. M, LiNS NETO, E. M. F, MELO, J. G, SANTOS, J. P. 2007. Medicinal Plants Of The Caatinga (Semi-Arid) Vegetation Of NE Brazil: A Quantitative Approach. Journal of Ethnopharmacology, África do Sul, 114:325-354. DOI: https://doi.org/10.1016/j.jep.2007.08.017

FERNANDES, M. C. A. 2000. Cultivo protegido do tomateiro, sob manejo orgânico, na região metropolitana do estado do Rio de janeiro. $1^{\text {a }}$ edição, 2:1-2, Série Agroecologia, Rio de Janeiro, RJ.

GARIGLIO, M. A, SAMPAIO, E., CESTARO L. A, KAGEYAMA, P. 2010. Uso sustentável e conservação dos recursos florestais da caatinga. $2^{\mathrm{a}}$ edição, $368 \mathrm{p}$, Serviço Florestal Brasileiro, Brasília, DF.

ICMBIO - Instituto Chico Mendes para a Conservação da Biodiversidade. 2018. Boas práticas na gestão de unidades de conservação. $3^{\mathrm{a}}$ edição, $127 \mathrm{p}$, Rio de Janeiro, RJ.

LEAL, I. R, SILVA, J. M. C, TABARELLI, M, LACHER-JR, T. E. 2005. Mudando o curso da conservação da biodiversidade na Caatinga do Nordeste do Brasil. Conservation International. Disponível em: <http://www.conservacao.org/publicacoes/files/19 Leal_et_al.pdf>. Acesso em 02 junho 2019.

LIMA, A. S, SILVA, F. L, SANTOS, J. M, SANTOS, J. G. R, ALVES, J. M, SOUSA, C. S. 2018. Produção da videira 'Isabel' em função de tipos e doses de biofertilizante. Agropecuária técnica, Areia, 39:238-245. DOI: https://doi.org/10.25066/agrotec.v39i3.42352

LORENZI, H., MATOS, F. J. A. 2008. Plantas Medicinais no Brasil: Nativas e exóticas. 2a edição, 544p, Instituto Plantarum, Nova Odessa, SP.

MARGULES, C. R, PRESSEY, R. L. 2000. Systematic conservation planning. Nature, London, 405:243-253.

MARTINELli, G., MORAES, M. A. 2013. Livro vermelho da flora do Brasil. $1^{\text {a }}$ edição, 1100p, Andrea Jakobsson Estúdio Editorial, Jardim Botânico do Rio de Janeiro, RJ.

MARTINS, S. V. 2007. Recuperação de matas ciliares. $2^{\mathrm{a}}$ edição, 255p, Centro de Produções Técnicas, Viçosa, MG.

MASCARENHAS, J. C, BELTRÃO, B. A, JUNIOR, L. C. S., MORAIS, F., MENDES, V. A., MIRANDA, J. L. F. 2005. Serviço Geológico do Brasil: Diagnóstico do município de Catolé do Rocha. $1^{\text {a }}$ edição, 21p, CPRM/PRODEEM, Recife, PE.

MELLO, M. S, FERNANDES, M. R. 2004. Adubação orgânica e adubação verde. EMATER, Belo Horizonte, MG.

PAES, J. B., MORAIS, V.M, LIMA, C. R. 2004. Resistência natural de nove madeiras do semi-árido brasileiro a fungos xilófagos em condições de laboratório. Revista Árvore, Viçosa, 28(2):275-282. DOI: http://dx.doi.org/10.1590/S010067622004000200014

PEREIRA, M. S. 2011. Manual técnico: Conhecendo e produzindo sementes e mudas da caatinga. $1^{\mathrm{a}}$ edição, 60p, Associação Caatinga, Fortaleza, CE.

Reserva da biosfera da caatinga. 2008. Disponível em: http://www. biosferadacaatinga.org.br. Acesso em: 15 jun. 2008 .

RIBASKI, J., LIMA, P. C. F., OLIVEIRA, V. R., DRUMOND, M. A. 2003. Sabiá (Mimosa caesalpiniaefolia) árvore de múltiplos usos no Brasil. 4p, Embrapa, Colombo, PR.

RODRIGUES, R. R., MARTINS, S. V., GANDOLFI, S. 2007. High diversity forest restoration in degraded areas: methods and projects in Brazil. First edition, 286p, Nova Science Publishers, New York, NY. 
SILVA, N. L. F. et al. Produção orgânica de mudas de essências florestais nativas e distribuição em comunidades rurais do semiárido paraibano. In: II Congresso Paraibano de Agroecologia \& IV Exposição Tecnológica, 2019. Anais... Caderno Verde de Agroecologia e Desenvolvimento Sustentável, Pombal, v. 9, n.7, e-7040, 2019.

SANTOS, J. G. R., SANTOS, E. C. X. R. 2008. Agricultura orgânica: teoria e prática. 1 edição, 230p, EDUEP, Campina Grande, PB.

SilvA, D. D. E., FELIZMinO, F. T. A, OLIVEIRA, M. G. 2015. Avaliação da degradação ambiental a partir da prática da cultura do feijão no município de Tavares-PB. Revista Holos, Natal, 8:148-165.

SILVA, F. L, LIMA, A. S, SANTOS, J. M, ALVES, J. M, SOUSA, C. S, SANTOS, J. G. R. 2019. Biofertilizantes na produção da videira Isabel. Revista verde de agroecologia e desenvolvimento sustentável, Pombal, 14:211-217. DOI: https://doi.org/10.18378/rvads.v14i2.6200.

\section{AGRADECIMENTOS}

Apoio financeiro: Fundação de Apoio à Pesquisa do Estado da Paraíba - FAPESQ. 